\title{
MATERNAL IMMUNITY AGAINST RABIES IN RACCOON DOGS
}

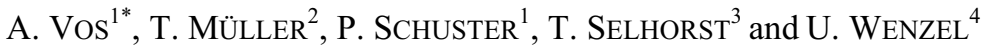 \\ ${ }^{1}$ IDT, PSF 214, 06855 Rosslau, Germany; ${ }^{2}$ Institute of Epidemiological Diagnostics, \\ Federal Research Centre for Virus Diseases of Animals, Wusterhausen, Germany; ${ }^{3}$ WHO \\ Collaborating Centre for Rabies Surveillance and Research, Wusterhausen, Germany; \\ ${ }^{4}$ Helenenstrasse 26a, 04279 Leipzig, Germany
}

(Received November 27, 2000; accepted February 8, 2001)

The objective of the study was to examine possible maternally transferred antibodies (maAb) against rabies in raccoon dogs. Ten cubs born from a rabiesimmune animal were bled on days $31,36,43,50,57$ and 64 post partum. The geometric mean titres of the cubs were $1.19,1.18,0.45,0.25,0.25$ and $0.16 \mathrm{IU} / \mathrm{ml}$, respectively. Up to 36 days post partum maAb were detected in all cubs at levels $\geq 0.5 \mathrm{IU} / \mathrm{ml}$ and at day 56 post partum all animals had maAb levels $<0.5 \mathrm{IU} / \mathrm{ml}$. Based on the results of this study, it is suggested that vaccine baits should not be distributed before July if the vaccination campaign is aimed at immunizing young raccoon dogs as well.

Key words: Raccoon dog, rabies, maternal immunity

Oral vaccination campaigns against rabies have resulted in the eradication of terrestrial wildlife rabies or at least led to a significant decrease in the number of rabies cases in participating European countries (Stöhr and Meslin, 1996; Müller and Schlüter, 1998; Vos et al., 2000). Vaccination strategies and techniques have been improved considerably since the first field trials in Switzerland in 1978. Recently, it was observed that maternally transferred immunity in young foxes interfered with the development of protective immunity to oral rabies vaccination (Müller et al., 1999). Hence, the timing of vaccination campaigns in late spring and early summer to vaccinate the young fox population has to be optimized accordingly. Nowadays, most rabies cases are reported from Eastern European countries. In several of these countries not only foxes (Vulpes vulpes) but also raccoon dogs (Nyctereutes procyonoides) are an important vector species of rabies. Thus, to further optimize vaccination strategies the biology of the raccoon dog should also be investigated. For this purpose, it was decided to conduct preliminary investigations on maternal immunity in raccoon dogs. The results of this study will be presented here and possible consequences for vaccination strategies will be discussed.

*Corresponding author; E-mail: ad.vos@idt-direct.de; Fax: +49 34901885797 


\section{Materials and method}

A female captive-held raccoon dog was vaccinated on 20 October 1999 with $10^{6.9}$ FFU SAD P5/88, a live modified oral rabies virus vaccine, by direct oral administration. The original SAD strain (Street-Alabama-Dufferin) was isolated from a rabid dog at the Centers for Diseases Control, USA, in 1935. It was propagated by passaging in mouse brain cells and subsequently adapted to BHK21 cells (Blancou and Meslin, 1996). The SAD P5/88 was isolated via adaptation of the SAD Berne strain to a higher producer cell line BHK21/Potsdam Clone 5 (Sinnecker et al., 1990). The female was bled on days 0, 21 and 83 post vaccination.

She gave birth to 10 cubs (6 males and 4 females) on 10 April 2000, 173 days post vaccination. The cubs were marked individually (transponder) and bled on days $31,36,43,50,57$ and 64 post partum.

All serum samples were evaluated by the Rapid Fluorescence Focus Inhibition Test (RFFIT) (Smith et al., 1973), with the modifications of this method as described by Cox and Schneider (1976). The rabies virus neutralizing antibody (VNA) titres were converted to International Units.

\section{Results}

The rabies VNA titre of the mother animal was $0.10,32.00$ and $74.80 \mathrm{IU} / \mathrm{ml}$ on day 0,21 and 83 post vaccination, respectively. The geometric mean titres (GMT) of the cubs were $1.19,1.18,0.45,0.25,0.25$ and $0.16 \mathrm{IU} / \mathrm{ml}$ on days 31 , $36,43,50,57$ and 64 post partum, respectively. The individual VNA titres of the cubs are shown in Table 1. In some animals a strong decline in VNA titres during a short period of time was observed. This is a result of the fact that the $50 \%$ reduction level of rabies virus, as determined by RFFIT, was calculated by inverse interpolation.

\section{Discussion}

Up to 36 days post partum maternal antibodies (maAb) were detected in all cubs at levels $\geq 0.5 \mathrm{IU} / \mathrm{ml}$. This level is considered as an arbitrarily defined threshold, indicative of protection against rabies infection (WHO, 1978). At day 56 post partum all cubs had maAb levels below the threshold of $0.5 \mathrm{IU} / \mathrm{ml}$. As only one litter was investigated during this preliminary study, these results cannot be considered representative for raccoon dogs in general. However, when the obtained maAb levels are compared with those obtained for fox cubs at a corresponding age (Müller et al., 1999), it can only be concluded that the former are relatively high. 
Table 1

Individual rabies neutralizing antibody titre (IU/ml) of the raccoon dog cubs as determined by RFFIT

\begin{tabular}{llllllll}
\hline \multirow{2}{*}{ Animal } & Sex & \multicolumn{7}{c}{ Age of cubs (days) } \\
\cline { 3 - 7 } & & 31 & 36 & 43 & 50 & 57 & 64 \\
\hline 1353 & female & 2.45 & 0.89 & 0.52 & 0.25 & 0.48 & 0.24 \\
2090 & male & 1.39 & 0.85 & 0.46 & 0.16 & 0.47 & 0.43 \\
2733 & female & 0.61 & 0.59 & 0.40 & 0.21 & 0.19 & 0.11 \\
3268 & male & 0.70 & 0.88 & 0.45 & 0.10 & 0.19 & 0.17 \\
4158 & male & 2.48 & 1.64 & 0.28 & 0.41 & 0.33 & 0.08 \\
4219 & male & 0.66 & 2.25 & 0.50 & 0.28 & 0.18 & 0.17 \\
4931 & female & 1.29 & 0.79 & 0.33 & 0.17 & 0.27 & 0.14 \\
6137 & female & 1.05 & 1.23 & 0.41 & 0.48 & 0.25 & 0.23 \\
8735 & male & 2.63 & 3.10 & 0.93 & 0.62 & 0.15 & 0.08 \\
9350 & male & 0.67 & 1.22 & 0.43 & 0.18 & 0.17 & 0.21 \\
\hline
\end{tabular}

Based on the results obtained for young foxes, it can be expected that an inhibition of the immune response to active oral vaccination as a result of maternally transferred immunity will take place. In foxes, the inhibition outlasted the time during which maAb were present at detectable levels. At an age of 8 weeks or older no differences in immune response after oral vaccination were observed between fox cubs born from rabies-immune and rabies-naïve vixens (Müller et al., 1999).

Most raccoon dogs are born between mid-April and mid-June with regional differences (Nowak, 1993; Stiebeling et al., 1999). Hence, if the objective of a vaccination campaign includes the immunization of young raccoon dogs, baits should not be distributed before July. Otherwise, a large segment of the young raccoon dog population will compete for baits but cannot be vaccinated effectively.

\section{References}

Blancou, J. and Meslin, F.-X. (1996): Modified live-virus rabies vaccines for oral immunization of carnivores. In: Meslin, F.-X., Kaplan, M. M. and Koprowski, H. (eds) Laboratory Techniques in Rabies. 4th edition. World Health Organization. Geneva. pp. 324-337.

Cox, J. H. and Schneider, L. G. (1976): Prophylactic immunization of humans against rabies by intradermal inoculation of human diploid cell culture vaccine. J. Clin. Microbiol. 3, 86-101.

Müller, T. and Schlüter, H. (1998): Oral immunization of red foxes (Vulpes vulpes) in Europe - A review. J. Etlik Vet. Microbiol. 9, 35-59.

Müller, T., Schuster, P., Wenzel, U., Vos, A., Selhorst, T. and Neubert, A. (1999): Maternal immunity and the immune response of fox cubs (Vulpes vulpes) to oral vaccination against rabies. Abstracts 10th Annual Rabies in the Americas Meeting, Nov. 14-19 1999, San Diego. USA. pp. 83. 
Nowak, E. (1993): Nyctereutes procyonoides Gray, 1834 - Marderhund. In: Stubbe, M. and Krapp, F. (eds) Handbuch der Säugetiere Europas. Band 5/I - Raubsäuger. Aula-Verlag. Wiesbaden. pp. 215-248.

Sinnecker, H., Apitzsch, H., Berndt, D., Schrader, C., Gogolin, J. and Egert, J. (1990): Die Entwicklung des Tollwutlebendimpfvirus SAD/Postdam 5/88 zur oralen Fuchsimpfung sowie seine Charakterisierung am Mausmodel. Mh. Vet. Med. 45, 77-78.

Smith, J. S., Yager, P. A. and Baer, G. M. (1973): A rapid reproducible test for determining rabies neutralizing antibody. Bull. World Health Organ. 48, 535-541.

Stiebeling, U., Schneider, R., Branding, C. and Samain, S. (1999): Zur Habitatnutzung des Marderhundes Nyctereutes procyonoides (Gray, 1834) in der uckermärkischen Agrarlandschaft: Ergebnisse zur Populationsdichte und -dynamik. Beitr. Jagd- u. Wildforsch. 24, 343-353.

Stöhr, K. and Meslin, F.-X. (1996): Progress and setbacks in the oral immunisation of foxes against rabies in Europe. Vet. Rec. 139, 32-35.

Vos, A., Müller, T., Schuster, P., Schlüter, H. and Neubert, A. (2000): Oral vaccination of foxes against rabies with SAD B19 in Europe, 1983-1998: A review. Vet. Bull. 70, 1-6.

WHO (1978): WHO/IABS Developments in Biological Standards. Symposium on the standardization of rabies vaccines for human use produced in tissue culture (Rabies III) 40, 268-270. 